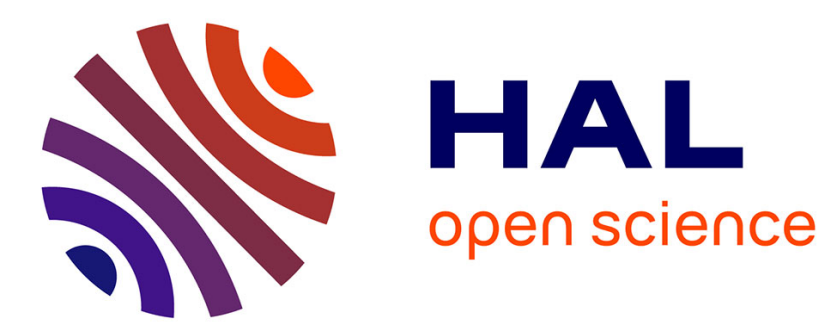

\title{
Effect of dendritic orientation on the high temperature oxidation kinetic of tantalum-containing nickel-base alloys
}

\author{
P. Berthod, C. Vebert, L. Aranda
}

\section{- To cite this version:}

P. Berthod, C. Vebert, L. Aranda. Effect of dendritic orientation on the high temperature oxidation kinetic of tantalum-containing nickel-base alloys. Journal of Materials Science, 2007, 42 (1), pp.352362. 10.1007/s10853-006-1033-4. hal-02190825

\section{HAL Id: hal-02190825 \\ https://hal.science/hal-02190825}

Submitted on 23 Jul 2019

HAL is a multi-disciplinary open access archive for the deposit and dissemination of scientific research documents, whether they are published or not. The documents may come from teaching and research institutions in France or abroad, or from public or private research centers.
L'archive ouverte pluridisciplinaire HAL, est destinée au dépôt et à la diffusion de documents scientifiques de niveau recherche, publiés ou non, émanant des établissements d'enseignement et de recherche français ou étrangers, des laboratoires publics ou privés. 


\title{
Effect of dendritic orientation of the high temperature oxidation kinetic of tantalum-containing nickel-base alloys
}

\author{
P. BERTHOD, C. VEBERT, L. ARANDA \\ Laboratoire de Chimie du Solide Minéral (UMR 7555), Faculté des Sciences et \\ Techniques, Université Henri Poincaré Nancy 1, BP 239, 54506 Vandoeuvre-Les- \\ Nancy Cedex, France \\ E-mail: patrice.berthod@centraliens-lille.org
}

\begin{abstract}
The aim of this work is the study of the possible effect of surface dendritic orientation on the high-temperature oxidation behavior of two chromia-forming Ni-base alloys with two tantalum contents $(3$ and $6 \%$ wt). Samples were prepared by special cutting orientation with regard to the external surface. Thermogravimetry tests were run at 1000,1100 and $1200^{\circ} \mathrm{C}$ and parabolic oxidation constants were considered. The mathematical process of the raw data was performed taking into account the effect of the transient oxidation. When the sample surface is mainly parallel to the dendritic network, the oxidation parabolic constant is higher than for a surface perpendicular to dendrites. The situation is contrary for the transient oxidation linear constant.
\end{abstract}

Keywords

High Temperature Oxidation, Cast Ni-base alloys, Dendritic Orientation

Post-print of the article J Mater Sci (2007) 42:352-362; DOI 10.1007/s10853-006-1033-4

\section{Introduction}

When obtained by a classical foundry way, the microstructure of metallic alloys depends on their chemical composition but also on the solidification conditions. For example the thermal gradient existing during the solidification governs the general direction of crystals growth, then dendrites and grain boundaries orientations. The latter are to be considered as special diffusion paths for species involved in the oxidation mechanisms [1]. Then it can be thought that the kinetics of high-temperature oxidation of superalloys could locally depend on dendrites orientation, as it was previously seen for different complex Co-base and Ni-base cast superalloys [2]. This possible effect was studied here at different high temperatures in the specific case of two chromia-forming Ni-base cast alloys which also contain tantalum.

\section{Effect of the thermal gradient on the dendrite orientation}

A microstructural evolution usually exists in alloys obtained by a classical foundry way, from the external surface towards the last point to solidify [3,4,5]. Near the mold wall (Fig. 1), among the first numerous very small crystals that appeared here, only a little number of them pursue their growth in the next zone. They are the ones which are favorably oriented with regard to the local thermal gradient, which is generally perpendicular to the mold wall. Thus, after a skin zone containing very small and randomly oriented grains, a columnar zone develops with an oriented microstructure. Here columns or dendrites (e.g. in the case of Ni- 
base alloys) are mainly perpendicular to the mold wall. The third zone, where solidification is finished, contains coarser dendrites that are randomly oriented again, because of the absence of any very marked gradient. After machining, a cast piece can present locally external surfaces with different grain sizes and also different orientations with regard to the subsurface dendritic network. Even if dendrites are not all either parallel or perpendicular to such surfaces, as it could be encountered for directionally solidified (DS) alloys, a global effect on the local oxidation kinetic may exist. The latter will be better studied with specially machined equiaxed alloys than with DS alloys.

\section{Materials and methods}

\subsection{Synthesis of the alloys}

Two Ni-base alloys were elaborated using a high frequency induction furnace under argon gas, and solidified in a water-cooled copper crucible (cone-shaped ingots of about $100 \mathrm{~g}$ and height $=$ maximal diameter $=30 \mathrm{~mm}$ ). They were synthesized from pure elements (more than 99.9\%): Ni (supplier: Eramet), Cr (supplier: Alfa Aesar), Ta (supplier: Aerometal) and C (graphite). The obtained chemical compositions are given in Table I.

\subsection{High temperature oxidation tests and mathematical processing}

Samples were parallelepipeds of approximately $10 \mathrm{~mm} \times 10 \mathrm{~mm} \times 2 \mathrm{~mm}$. Cutting orientation was chosen in order to obtain square faces that are either parallel or perpendicular to dendrites (Fig. 2). For each sample, the total mass gain kinetic is the sum of two contributions which can be uncoupled. The oxidation rates of the parallel surface $S_{/ /}$and of the perpendicular surface $S_{\perp}$ exist together in the global mass gain (Eq. 1). Then, the two parabolic constants $\mathrm{Kp}_{/ /}$and $\mathrm{Kp}_{\perp}$, that describe the two local oxidation rates, appear as the two unknown values of a linear equation (Eq. 2), in which they are related to the measured global constant Kp. For a same alloy and a same temperature, solving the two linear equations (Eq. 2) written for the two types of samples gives both $\mathrm{Kp}_{/ /}$and $\mathrm{Kp}_{\perp}$.

$$
\begin{aligned}
& \frac{\Delta \mathrm{m}}{\mathrm{S}}(\mathrm{t})=\frac{\Delta \mathrm{m}_{/ /}(\mathrm{t})+\Delta \mathrm{m}_{\perp}(\mathrm{t})}{\mathrm{S}_{/ /}+\mathrm{S}_{\perp}}=\frac{\mathrm{S}_{/ /}}{\mathrm{S}_{/ /}+\mathrm{S}_{\perp}} \sqrt{2 \cdot \mathrm{Kp}_{/ /}} \cdot \sqrt{\mathrm{t}}+\frac{\mathrm{S}_{\perp}}{\mathrm{S}_{/ /}+\mathrm{S}_{\perp}} \sqrt{2 \cdot \mathrm{Kp}_{\perp}} \cdot \sqrt{\mathrm{t}} \\
& \frac{\mathrm{S}_{/ /}}{\mathrm{S}} \sqrt{2 \cdot \mathrm{Kp}_{/ /}}+\frac{\mathrm{S}_{\perp}}{\mathrm{S}} \sqrt{2 \cdot \mathrm{Kp}_{\perp}}=\sqrt{2 \cdot \mathrm{Kp}}
\end{aligned}
$$

Oxidation runs were performed using a Setaram TGA92 thermobalance. Alloys were exposed at $1000^{\circ} \mathrm{C}, 1100^{\circ} \mathrm{C}$ and $1200^{\circ} \mathrm{C}$ for 100 hours under a flow of synthetic air $\left(80 \% \mathrm{~N}_{2}-\right.$ $20 \% \mathrm{O}_{2}$ ) of about $1,51 / \mathrm{min}$. The heating rate, until reaching the targeted temperature, and the cooling rate, for the return to room temperature, were $20^{\circ} \mathrm{C} / \mathrm{min}$ and $10^{\circ} \mathrm{C} / \mathrm{min}$ respectively. The recording of the mass gain was made every 74 seconds.

All the obtained mass gain curves showed an initial linear part (of the (Eq. 3) type) and a following parabolic part (of the (Eq. 5) type) by which it was possible to determine a parabolic Kp constant. The oxide thickness obtained before the beginning of the parabolic oxidation must be taken into account for the determination of $\mathrm{Kp}$. Then, to process the obtained files, we applied the following procedure. 
$\frac{\Delta \mathrm{m}}{\mathrm{S}}=\mathrm{K}_{1} \cdot \mathrm{t} \quad$ (3) $\quad \mathrm{K}_{1}=\mathrm{K}_{\mathrm{l}_{\mathrm{o}}} \cdot \mathrm{e}^{\frac{-\mathrm{Q}}{\mathrm{R} \cdot \mathrm{T}}} \quad$ (4) $\quad \frac{\Delta \mathrm{m}}{\mathrm{S}}=\sqrt{2 \cdot \mathrm{Kp}} \sqrt{\mathrm{t}}$

Oxidation during heating and linear isothermal oxidation each induced a first mass gain before parabolic oxidation took place. The initial mass gain is the sum (Eq. 6) of a heating part (first term) and a linear isothermal part (second term):

$$
\frac{\Delta \mathrm{m}_{\mathrm{o}}}{\mathrm{S}}=\mathrm{K}_{\mathrm{l}_{\mathrm{o}}} \cdot \int_{273 \mathrm{~K}}^{\mathrm{T}_{\text {test }}} \mathrm{e}^{\frac{-\mathrm{Q}}{\mathrm{R} \cdot \mathrm{T}(\mathrm{t})}} \cdot \mathrm{dt}+\left(\frac{\Delta \mathrm{m}}{\mathrm{S}}\right)_{\mathrm{L}} \approx \mathrm{K}_{\mathrm{I}_{\mathrm{o}}} \cdot\left(\sum_{\mathrm{n}=1}^{\mathrm{N}} \mathrm{e}^{\frac{-\mathrm{Q}}{\mathrm{R} \cdot\left(273 \mathrm{~K}+\mathrm{R}_{\mathrm{H}} \cdot \mathrm{n} \cdot \Delta \mathrm{t}\right)}}\right) \cdot \Delta \mathrm{t}+\left(\frac{\Delta \mathrm{m}}{\mathrm{S}}\right)_{\mathrm{L}}
$$

where:

$\mathrm{K}_{\mathrm{lo}}$ and Q, the Arrhenius constants of the linear constant $\mathrm{K}_{1}$ (Eq. 4), were deduced from the $\mathrm{K}_{1}$ values obtained for 1273, 1373 and 1473K,

- $\quad \mathrm{R}_{\mathrm{H}}$ is the heating rate,

- $\Delta t$ the recording time increment $(74 \mathrm{~s})$,

$\mathrm{N}$ the number of recording paths during the heating $\mathrm{N}=\frac{\mathrm{T}_{\text {test }}-273 \mathrm{~K}}{\mathrm{R}_{\mathrm{H}} \cdot \Delta \mathrm{t}}$ ),

and $\left(\frac{\Delta \mathrm{m}}{\mathrm{S}}\right)_{\mathrm{L}}$ is the mass gain during the isothermal linear oxidation.

When the external oxide scale becomes continuous, the Wagner's differential equation describes the parabolic mass gain kinetic $\Delta \mathrm{m}_{\mathrm{P}} / \mathrm{S}$ (Eq. 7). Its integration leads to (Eq. 8).

$$
\frac{\mathrm{d}\left(\Delta \mathrm{m}_{\mathrm{P}} / \mathrm{S}\right)}{\mathrm{dt}}=\frac{\mathrm{Kp}}{\left(\Delta \mathrm{m}_{\mathrm{p}} / \mathrm{S}+\Delta \mathrm{m}_{\mathrm{o}} / \mathrm{S}\right)}(7) \quad \mathrm{Kp}=\frac{1}{2 \cdot\left(\mathrm{t}-\mathrm{t}_{\mathrm{o}}\right)} \cdot\left[\left(\Delta \mathrm{m}_{\mathrm{p}} / \mathrm{S}+\Delta \mathrm{m}_{\mathrm{o}} / \mathrm{S}\right)^{2}-\left(\Delta \mathrm{m}_{\mathrm{o}} / \mathrm{S}\right)^{2}\right]
$$

Knowing the values of $\Delta \mathrm{m}_{\mathrm{o}} / \mathrm{S}$ and of $\mathrm{t}_{\mathrm{o}}$ (instant at which the parabolic oxidation took place) the value of $\mathrm{Kp}$ can be obtained without any error caused by the mass gain obtained before.

For 1100 and $1200^{\circ} \mathrm{C}$, the volatilization of the external $\mathrm{Cr}_{2} \mathrm{O}_{3}$ scale (partly oxidized into gaseous $\mathrm{CrO}_{3}$ ) was taken into account by adding the $\mathrm{Kv}$. $\mathrm{t}$ quantity (Eq. 9), in order to get a value closer to the real $\mathrm{Kp}$ constant. The volatilization constant $\mathrm{Kv}$ is the rate of mass loss per surface unit area due to the volatilization of re-oxidized chromia. The values of $\mathrm{Kv}$ for $1100^{\circ} \mathrm{C}$ and $1200^{\circ} \mathrm{C}$ used here were the ones that were directly determined in a previous work [6] for similar alloys: $\mathrm{Kv}=2.4 \cdot 10^{-10} \mathrm{~g} \cdot \mathrm{cm}^{-2} \cdot \mathrm{s}^{-1}\left(1100^{\circ} \mathrm{C}\right)$ and $46 \cdot 10^{-10} \mathrm{~g} \cdot \mathrm{cm}^{-2} \cdot \mathrm{s}^{-1}$ $\left(1200^{\circ} \mathrm{C}\right)$.

$\mathrm{Kp}=\frac{1}{2 \cdot\left(\mathrm{t}-\mathrm{t}_{\mathrm{o}}\right)} \cdot\left[\left(\left(\Delta \mathrm{m}_{\mathrm{p}} / \mathrm{S}+\mathrm{Kv} \cdot \mathrm{t}\right)+\Delta \mathrm{m}_{\mathrm{o}} / \mathrm{S}\right)^{2}-\left(\Delta \mathrm{m}_{\mathrm{o}} / \mathrm{S}\right)^{2}\right]$

To finish, on the time range where oxidation is linear on both the part parallel to dendrites and the perpendicular one, the global $\mathrm{K}_{1}$ is a linear combination of two contributions (Eq. 10), like for the parabolic constants (Eq. 2). The uncoupling (Eq. 10) leads to the $\mathrm{K}_{\mathrm{l} / /}$ and $\mathrm{K}_{1} \perp$ constants.

$$
\frac{\mathrm{S}_{/ /}}{\mathrm{S}} \cdot \mathrm{K}_{1 / /}+\frac{\mathrm{S}_{\perp}}{\mathrm{S}} \cdot \mathrm{K}_{1 \perp}=\mathrm{K}_{1}
$$




\subsection{Examination of the oxidized samples}

After testing, the surface of the oxidized samples became electrically conductive by a gold layer deposited by cathodic plasma pulverization. Then the external chromia layer was mechanically protected by a sufficiently thick electrolytic nickel coating. Thereafter samples were cut, embedded in resin, polished and examined using a Philips XL30 Scanning Electron Microscope (SEM), under a $20 \mathrm{kV}$ acceleration voltage. Spot analysis and concentrations profiles were performed using Energy Dispersive Spectroscopy (EDS) coupled with the SEM. Identification of phases like carbides and oxides and $\mathrm{Cr}$ and $\mathrm{Ta}$ contents profiles were performed with a Cameca SX100 WDS microprobe.

\section{Results}

\subsection{Initial microstructures of the alloys}

The bulk microstructures of the as-cast alloys are illustrated by the SEM photographs presented in Fig. 3. The two alloys own first an austenitic matrix which solidified with the form of dendrites. They also contain two types of carbides in the grain boundaries. Chromium carbides and tantalum carbides precipitated at the end of solidification forming an eutectic with matrix, with the $\mathrm{Cr}_{7} \mathrm{C}_{3}$ and $\mathrm{TaC}$ stoechiometries. These carbides are known to be very useful for strengthening at high temperatures [7,8]. Carbides are obviously more present in the high carbon alloy ( $\mathrm{H}$ alloy) than in the low carbon one ( $\mathrm{L}$ alloy).

\subsection{Oxidation rates}

Oxidation runs were performed on the two alloys for the two main dendrites orientations and for the three temperatures 1000,1100 and $1200^{\circ} \mathrm{C}$. All curves started by a linear part when temperature reached the targeted one. Thereafter parabolic oxidation acted and led to a more or less long parabolic part of curve. Indeed, in some cases detachments of the external and continuous oxide scale obviously occurred and induced jumps of the mass gain. Some of thermogravimetry tests were started again but detachments still existed; fortunately the parabolic part was always sufficiently long (about 50 hours) to allow the determination of the parabolic constants. Fig. 4 shows all the obtained curves from the beginning of the parabolic oxidation (i.e. after isothermal transient linear is finished), and after addition of the Kv.t linear term to correct from the mass loss by chromia volatilization for 1100 and $1200^{\circ} \mathrm{C}$. The two mass gain curves corresponding to a same alloy and a same temperature but for the two cutting orientations, were plotted together in a same graph.

It already appears on this example that dendrite orientation seems have an effect on the oxidation rate. Indeed, for $1200^{\circ} \mathrm{C}$ the mass gain curve of $\mathrm{L}$ alloy for the parallel orientation is above the other one. Everywhere along the curves, the slope is also higher for the first one than for the other. For $\mathrm{H}$ alloy at the same temperature it is especially the slope that shows a lightly faster oxidation for the parallel orientation than for the other one. For the two other temperatures the comparison is more difficult, especially for $\mathrm{H}$ alloy at $1000^{\circ} \mathrm{C}$ for which the perpendicular orientation seemed to favor detachment of the oxide scale during thermogravimetry tests.

Thereafter it was mathematically proceeded as previously explained. Table II shows the values of $K_{1}$ obtained for all the oxidation tests and the calculated $\frac{\Delta \mathrm{m}_{\mathrm{o}}}{\mathrm{S}}$ mass gains already existing before the parabolic oxidation. For each sample, as is to say each alloy and 
each main orientation, the linear constant logically increases with temperature and, effectively follows an Arrhenius law (example in Fig. 5). The activation energies presented in the last column are those which were employed to estimate the initial mass gains by oxidation during heating before test. One also can see that the linear constants seem to be higher for $\mathrm{H}$ alloy than for $\mathrm{L}$ alloy (except for $1000^{\circ} \mathrm{C}$ ), and when the external surface is mainly perpendicular than parallel to dendrites (at all temperatures). The same observations can be done for the mass gains before parabolic oxidation. This tendency is enhanced after uncoupling as shown in Table III in which it clearly appears that the orientation has directly an influence of the linear oxidation rate.

After having exploited the values of the global linear constants, the global parabolic constants were obtained. Table IV displays their values. They also increase with temperature and showed a dependence of the orientation, especially at $1200^{\circ} \mathrm{C}$. Indeed, the global $\mathrm{Kp}$ values are almost equals between the two orientations for $1000^{\circ} \mathrm{C}$ and $1100^{\circ} \mathrm{C}$ (except for the $\mathrm{L}$ alloy at $1100^{\circ} \mathrm{C}$ ). But at $1200^{\circ} \mathrm{C}$, it appears that the samples mainly parallel to dendrites oxidized faster than the samples mainly perpendicular to dendrites. Like for the linear constants, the uncoupling enhances the differences. For $1200^{\circ} \mathrm{C}$ the parabolic oxidation rate of the surface elements parallel to dendrites are sensibly higher than the perpendicular ones. For the two lowest temperatures the differences that appeared after uncoupling are only due to the calculation. However, the opposite difference observed for $\mathrm{L}$ alloy at $1100^{\circ} \mathrm{C}$ still exists and is increased after uncoupling. The parabolic constant of each type of surface also follows an Arrhenius law (Fig. 6), the activation energies of which are given in Table V.

\subsection{Observation of the oxidation front}

After oxidation tests all samples were metallographically prepared and examined using a Scanning Electron Microscope. Unfortunately, the chromia layer had totally quitted the surface of the samples, then could not be examined. On the contrary it was possible to study the sub-surface deterioration of the alloy due to oxidation (Fig. 7).

From the external surface, all samples exhibit a first zone having lost its initial carbides. For each alloy the depth of this carbide-free zone increases with temperature. Its depth also seems to be higher for the L alloy than for the $\mathrm{H}$ alloy, the carbide network of which is more dense.

On a thin outer part this zone also contains internal oxides, which were identified as being $\mathrm{CrTaO}_{4}$ by WDS microanalysis. These oxides seem to be more present for the $\mathrm{H}$ alloy than for the L alloy which contains less tantalum. These oxides almost form a continuous layer along the external surface of the $\mathrm{H}$ alloy. Between the carbide-free zone and the bulk we often encounter an intermediate zone in which carbides are different compared to the bulk: darker, coarser or having precipitated in the matrix. These phenomena were explained in previous works [9 to 11] in others alloys also reinforced by carbides, as resulting from an inwards diffusion of carbon atoms released by the dissolving carbides.

Concerning the dendritic orientation, one does not see real differences on both the carbide-free zone and the internal oxides between the main faces of the two types of samples for a same alloy and a same temperature.

\subsection{WDS profiles}

The evolution of contents of both chromium and tantalum were analyzed from the external surface towards the bulk until the values remain constant. Two profiles were 
performed by sample and the results that are presented respectively in Table VI and Table VII, are the obtained average values.

The chromium profiles show two successive gradients for all samples at $1000^{\circ} \mathrm{C}$ and $1100^{\circ} \mathrm{C}$, the first one corresponding to the carbide-free zone for 1000 and $1100^{\circ} \mathrm{C}$, while the second one exists more deeper in the bulk where carbides remained. However the second gradient is almost negligible for $1200^{\circ} \mathrm{C}$ and it can be considered that it does not exist (Fig. 9). For all alloys, when the temperature increases, the depths of the two gradients also increase while the values of the gradient decrease. Between the alloys the gradients are higher and their depths are smaller for the $\mathrm{L}$ alloy than for the $\mathrm{H}$ alloy at $1000^{\circ} \mathrm{C}$ while these tendencies disappear for the two highest temperatures. Between the two orientations, some differences can be pointed out. Indeed, for $1000^{\circ} \mathrm{C}$ and for the two alloys $\mathrm{Cr}$ gradients seems to be greater for the parallel orientation than for the perpendicular one, while such an order does not exist for $1100^{\circ} \mathrm{C}$. However the first tendency as $1000^{\circ} \mathrm{C}$ seems to be found again for $1200^{\circ} \mathrm{C}$.

The tantalum profiles often present two successive gradients, especially in the case of $\mathrm{L}$ alloy. Like for chromium the gradients decrease and their depths increase when temperature increases. Their gradients are more accentuated for $\mathrm{H}$ alloy than for $\mathrm{L}$ alloy, because of the higher Ta content of the first one. The total depletion is deeper for the $\mathrm{L}$ alloy than for $\mathrm{H}$ alloy. Except for the $\mathrm{H}$ alloy at $1000^{\circ} \mathrm{C}$, the orientation does not sensibly influence the $\mathrm{Ta}$ gradients.

\section{Discussion}

Thermogravimetry results showed that the dendritic orientation can have an effect on the oxidation rate of these two nickel alloys. This was already seen on samples, at all temperatures for linear oxidation constants but only at $1200^{\circ} \mathrm{C}$ for the parabolic constant, but it appeared more marked by considering the two uncoupled contributions.

We saw first that the transient linear oxidation is faster when dendrites are mainly perpendicular to the local external surface, than when they are parallel. The same observation can be made for the total mass gain obtained before the parabolic oxidation takes place.

To explain that, one can say that perpendicular orientation is probably favorable to a more exposed position of emerging sub-surface carbides (i.e. their very oxidable $\mathrm{Cr}$ and $\mathrm{Ta}$ constitutive elements) to oxidation, in terms of density as well as of homogeneity. Then transient oxidation and early linear mass gain can be faster in this case than for the other orientation for which the presence of primary dendrites arms can act, here and there, as oriented barriers between interdendritic carbides and the external surface. The general nucleation of chromia (average number of nucleus per surface unit) could be also greater for the perpendicular orientation than for the parallel one, for the same reasons. The first lateral growth of the chromia can be accelerated until all these $\mathrm{Cr}_{2} \mathrm{O}_{3}$ crystals meet one another, leading to a faster mass gain during the transient oxidation for the perpendicular orientation than for the parallel one.

On the contrary, the Wagner's parabolic oxidation tends to be lower when dendrites are perpendicular to surface than when they are parallel. The same effect of the dendritic orientation on the values of the parabolic constant $\mathrm{Kp}$ was already found [2], but more marked, for a similar alloy (Ni-30Cr-0.7C-7.5Fe-7.5W) for which a sample with a surface mainly parallel to dendrites exhibited a higher $\mathrm{Kp}$ than a sample mainly perpendicular to dendrites $\left(\mathrm{Kp}_{/ /} \sim 3 . \mathrm{Kp}_{\perp}\right.$ at $1000^{\circ} \mathrm{C}$ and $\mathrm{Kp}_{/ /} \sim 2 \mathrm{Kp}_{\perp}$ at $\left.1100^{\circ} \mathrm{C}\right)$. Here, the real differences that were observed in this work are at $1200^{\circ} \mathrm{C}$ for the two alloys (but more marked for $\mathrm{L}$ alloy). The parabolic constant for the parallel orientation is twice the one for the perpendicular 
orientation for $\mathrm{L}$ alloy, while, for $\mathrm{H}$ alloy, the parallel parabolic constant is greater than the perpendicular one, of $25 \%$ only.

The faster oxidation for the parallel orientation could be explained by a less homogeneous chromia scale structure due to the dendrites orientation. Indeed grain boundaries are parallel to surface and then may induce an anisotropy (or orientation along the external surface) for the conditions of formation of external oxides. Thus one can think that the quality of external chromia scale can depend on this special texture, then the chromia scale is less protective for the alloy, i.e less favorable to a better resistance to the diffusion of the species involved by oxidation. Despite of a greater difficulty due to diffusion paths not well oriented, chromium then diffuses faster towards the oxidation front. This can be more accentuated in the case of L alloy, for which the emerging interdendritic carbides are less dense and the primary dendrite arms coarser, than for $\mathrm{H}$ alloy for which this heterogeneity is less marked because of a lower surface fraction of emerging matrix. When one sees to the chromium depletion of the parallel L alloy sample, it appears that more chromium was concerned by oxidation at $1200^{\circ} \mathrm{C}$ (greater gradients and lightly deeper depletion zone) than for the perpendicular one.

Unfortunately, no analysis was done on the chromia scale since this one systematically quitted the alloy during cooling. Like for all chromia-forming alloys this phenomenon is possible since the average thermal expansion coefficient (about $7.10^{-6 \circ} \mathrm{C}^{-1}$ ) is sensibly lower than our alloys' one $\left(10.10^{-6 \circ} \mathrm{C}^{-1}\right)$, but the chromia exfoliation is worsen by the inner development of $\mathrm{CrTaO}_{4}$ oxide just under chromia that obstruct the adhesion of chromia of the substrate. Slower cooling rates obviously were not able to prevent this loss of the external oxide scale for these tantalum-rich alloys. Concerning the sub-surface $\mathrm{CrTaO}_{4}$.

One can also remark that the inner development of the $\mathrm{CrTaO}_{4}$ has maybe also decreased the effect of dendritic orientation when the results of this study are compared to previous ones [2] obtained for a nickel alloy without tantalum.

The greater differences about oxidation rates (linear and parabolic), and also subsurface microstructure and concentration profiles, were also seen between the two alloys: on the one hand lower transient and parabolic oxidation kinetics, and on the other hand deeper carbide-free zone, higher $\mathrm{Cr}$ gradients at $1000^{\circ} \mathrm{C}$ but deeper Ta depletions, were clearly found for the $\mathrm{L}$ alloy compared to the $\mathrm{H}$ alloy. Such results were already found in previous studies concerning other carbides-strengthened cast alloys.

\section{Conclusions}

The dependence of the local oxidation rate on the dendritic orientation was found again in the case of tantalum-containing nickel alloys, but essentially for $1200^{\circ} \mathrm{C}$. A second effect was also seen on the transient oxidation. The quantification of the latter, allowed by the determination of the linear $\mathrm{K}_{1}$ constants and of their law of variation with temperature, led to see also a dependence of this first stage of oxidation on the dendritic orientation.

These results confirm others obtained in previous works on other equiaxed cast alloys. The dendritic orientation obviously influences the oxidation behavior. But the mechanisms remain to be more clearly explained, since it was not possible to examine the structure of the external chromia layer, a problem which is probably due to inner oxidation of tantalum. Future works, on alloys which can more easily conserve their external oxide until return to room temperature, will certainly allow to better understand the phenomena responsible of this influence of the dendritic orientation on the oxidation behavior. 


\section{Acknowledgements}

The authors thank J. Demange, Y. Ravaux and A. Kohler, of the Microanalysis Common Service of the Faculty of Science of Nancy for their contribution at this work.

\section{References}

[1] P. KOFSTAD, in "High Temperature Corrosion" (Elsevier, 1988)

[2] P. BERTHOD, S. RAUDE, A.S. RENCK, C. RAPIN, R. PODOR and P. STEINMETZ, Mat. Sci. Forum, 461-464 (2004) 1117.

[3] W. KURZ and D.J. FISHER, in "Fundamentals of solidification" (Trans. Tech Publications, 1989)

[4] G. LESOULT, M59 (Techniques de l'Ingénieur, 1989)

[5] G. LESOULT, M58 (Techniques de l'Ingénieur, 1986)

[6] J. DI MARTINO, PhD Thesis (Université de Nancy 1, 2002)

[7] E.F. BRADLEY, in "Superalloys : A technical guide" (ASM International, 1988)

[8] C.T. SIMS and W.C. HAGEL, in "The superalloys" (John Wiley \& Sons, 1972)

[9] P. BERTHOD, S. MICHON, J. DI MARTINO, S. MATHIEU, S. NOEL, R. PODOR and C. RAPIN, CALPHAD 27/3 (2003) 279.

[10] P. BERTHOD, S. MICHON, S. MATHIEU, R. PODOR, C. RAPIN and P. STEINMETZ, Mat. Sci. Forum 461-464 (2004) 1173.

[11] P. BERTHOD, C. VEBERT, L. ARANDA, R. PODOR, C. RAPIN, Oxidation of Metals 63 1/2 (2005) 57. 
TABLE I Chemical compositions of the two studied nickel-base alloys

\begin{tabular}{ccccc}
\hline \multirow{2}{*}{ Alloys } & \multicolumn{4}{c}{ Weight contents (\%) } \\
\cline { 2 - 5 } H alloy & Ni & $\mathrm{Cr}$ & $\mathrm{C}$ & Ta \\
Bal. & 30 & 0.40 & 5.4 \\
L alloy & Bal. & 30 & 0.20 & 2.0 \\
\hline
\end{tabular}

TABLE II Global oxidation linear $\mathrm{K}_{1}$ constants $\left(10^{-8} \mathrm{~g} \cdot \mathrm{cm}^{-2} \cdot \mathrm{s}^{-1}\right)$ and values of the calculated $\frac{\Delta \mathrm{m}_{\mathrm{o}}}{\mathrm{S}}$ mass gains already existing before the parabolic oxidation (in $\mathrm{mg} / \mathrm{cm}^{2}$ )

\begin{tabular}{|c|c|c|c|c|c|}
\hline Alloy & iture & $1000^{\circ} \mathrm{C}$ & $1100^{\circ} \mathrm{C}$ & $1200^{\circ} \mathrm{C}$ & $\begin{array}{c}\text { Activation } \\
\text { energy } \\
\left(\mathrm{kJ} \cdot \mathrm{mol}^{-1}\right)\end{array}$ \\
\hline \multirow{2}{*}{$\mathrm{H}$ alloy } & // & $\begin{array}{c}1.12 \\
(0.651 \mathrm{mg} / \mathrm{cm} 2)\end{array}$ & $\begin{array}{c}8.84 \\
(1.25 \mathrm{mg} / \mathrm{cm} 2)\end{array}$ & $\begin{array}{c}33.3 \\
(4.82 \mathrm{mg} / \mathrm{cm} 2)\end{array}$ & 265 \\
\hline & $\perp$ & $\begin{array}{c}1.29 \\
(1.06 \mathrm{mg} / \mathrm{cm} 2)\end{array}$ & $\begin{array}{c}11.8 \\
(1.32 \mathrm{mg} / \mathrm{cm} 2)\end{array}$ & $\begin{array}{c}41.7 \\
(5.52 \mathrm{mg} / \mathrm{cm} 2)\end{array}$ & 272 \\
\hline \multirow[t]{2}{*}{ L alloy } & // & $\begin{array}{c}2.65 \\
(0.113 \mathrm{mg} / \mathrm{cm} 2)\end{array}$ & $\begin{array}{c}3.58 \\
(2.08 \mathrm{mg} / \mathrm{cm} 2)\end{array}$ & $\begin{array}{c}14.2 \\
(4.18 \mathrm{mg} / \mathrm{cm} 2)\end{array}$ & 129 \\
\hline & $\perp$ & $\begin{array}{c}2.63 \\
(0.096 \mathrm{mg} / \mathrm{cm} 2)\end{array}$ & $\begin{array}{c}4.13 \\
(2.52 \mathrm{mg} / \mathrm{cm} 2)\end{array}$ & $\begin{array}{c}20.6 \\
(4.59 \mathrm{mg} / \mathrm{cm} 2) \\
\end{array}$ & 158 \\
\hline
\end{tabular}

TABLE III Uncoupled oxidation $\mathrm{K}_{1}$ constants $\left(10^{-8} \mathrm{~g} \cdot \mathrm{cm}^{-2} \cdot \mathrm{s}^{-1}\right)$

\begin{tabular}{|c|c|c|c|c|c|}
\hline Alloy & Temperature & $1000^{\circ} \mathrm{C}$ & $1100^{\circ} \mathrm{C}$ & $1200^{\circ} \mathrm{C}$ & $\begin{array}{l}\text { Activation } \\
\text { energy } \\
\left(\mathrm{kJ} \cdot \mathrm{mol}^{-1}\right)\end{array}$ \\
\hline \multirow{2}{*}{$\mathrm{H}$ alloy } & $\mathrm{K}_{1 / /}$ & 1.02 & 8.20 & 27.2 & 257 \\
\hline & $\mathrm{K}_{1 \perp}$ & 1.60 & 13.4 & 48.4 & 267 \\
\hline \multirow{2}{*}{ L alloy } & $\mathrm{K}_{1 / /}$ & 2.65 & 3.14 & 11.7 & 113 \\
\hline & $\mathrm{K}_{1 \perp}$ & 2.63 & 4.53 & 23.5 & 169 \\
\hline
\end{tabular}


TABLE IV Global oxidation parabolic Kp constants $\left(10^{-12} \mathrm{~g}^{2} \cdot \mathrm{cm}^{-4} \cdot \mathrm{s}^{-1}\right)$

\begin{tabular}{lcccc}
\hline & Temperature & $1000^{\circ} \mathrm{C}$ & $1100^{\circ} \mathrm{C}$ & $1200^{\circ} \mathrm{C}$ \\
Alloy & & 3.24 & 24.9 & 137 \\
\hline H alloy & $/ /$ & 3.20 & 24.8 & 126 \\
& $\perp$ & & & \\
& & & 13.3 & 117 \\
L alloy & $\perp$ & 2.46 & 16.1 & 81.5 \\
\hline
\end{tabular}

TABLE V Uncoupled oxidation parabolic constants $\left(10^{-12} \mathrm{~g}^{2} \cdot \mathrm{cm}^{-4} \cdot \mathrm{s}^{-1}\right)$

\begin{tabular}{|c|c|c|c|c|c|}
\hline Alloy & Temperature & $1000^{\circ} \mathrm{C}$ & $1100^{\circ} \mathrm{C}$ & $1200^{\circ} \mathrm{C}$ & $\begin{array}{c}\text { Activation } \\
\text { energy } \\
\left(\mathrm{kJ} . \mathrm{mol}^{-1}\right)\end{array}$ \\
\hline \multirow{2}{*}{$\mathrm{H}$ allo } & $\mathrm{Kp} / /$ & 3.26 & 24.9 & 145 & 296 \\
\hline & $\mathrm{Kp}_{\perp}$ & 3.12 & 24.7 & 117 & 283 \\
\hline \multirow{2}{*}{$\mathrm{L}$ allo } & $\mathrm{Kp} / /$ & 2.49 & 11.2 & 133 & 308 \\
\hline & $\mathrm{Kp}_{\perp}$ & 2.15 & 18.2 & 67.5 & 270 \\
\hline
\end{tabular}


TABLE VI Mean values of chromium gradients from the external surface

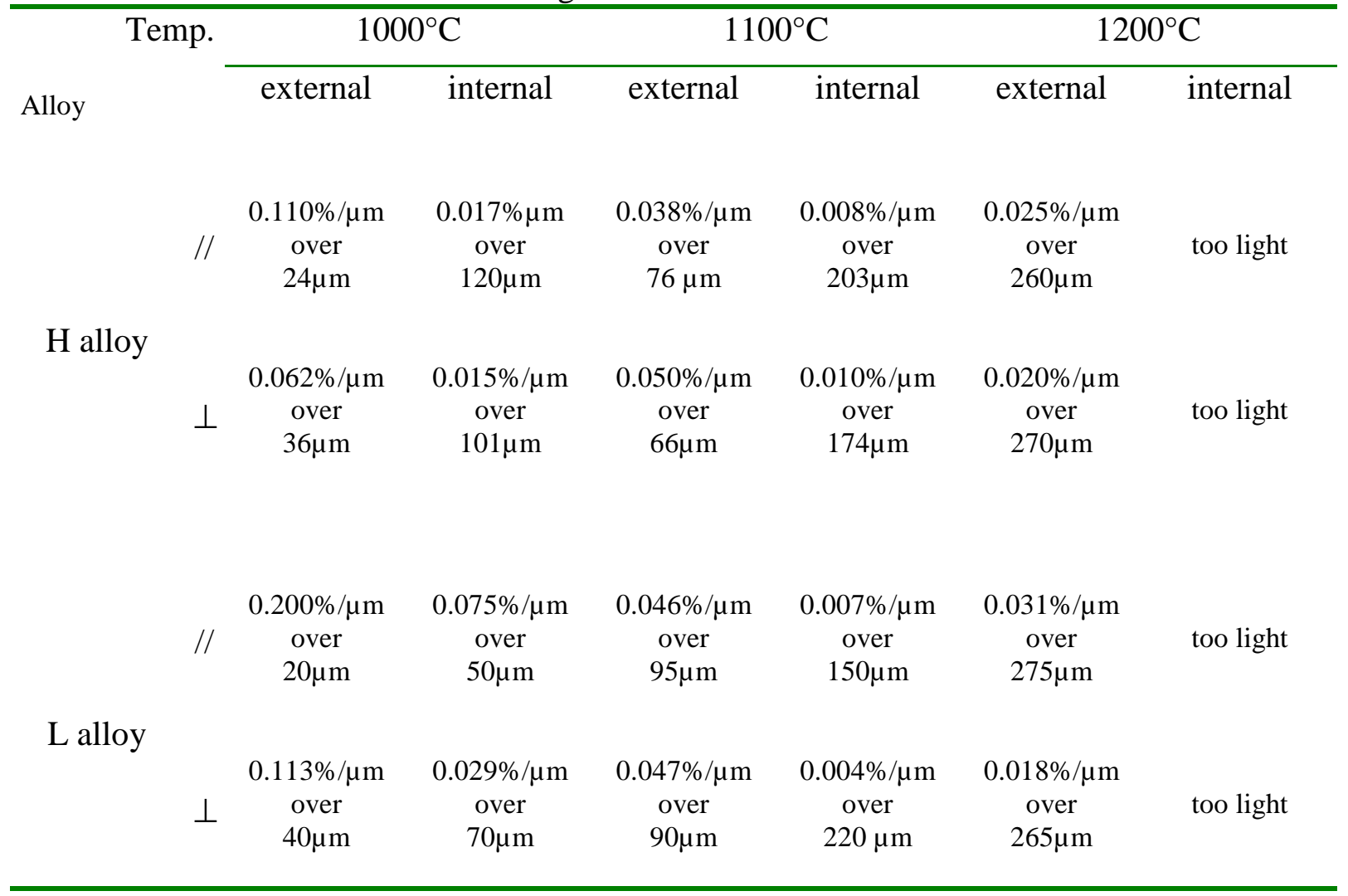

TABLE VII Mean values of tantalum gradients from the external surface

Temp.

\begin{tabular}{|c|c|c|c|c|}
\hline Alloy & & $1000^{\circ} \mathrm{C}$ & $1100^{\circ} \mathrm{C}$ & $1200^{\circ} \mathrm{C}$ \\
\hline H alloy & $/ /$ & $0.054 \% / \mu \mathrm{m}$ over $70 \mu \mathrm{m}$ & $0.038 \% / \mu \mathrm{m}$ over $130 \mu \mathrm{m}$ & $\begin{array}{c}0.028 \% / \mu \mathrm{m} \text { over } 130 \mu \mathrm{m} \\
\text { then } \\
0.008 \% / \mu \mathrm{m} \text { over } 80 \mu \mathrm{m}\end{array}$ \\
\hline \multirow{3}{*}{ L alloy } & $\perp$ & $0.095 \% / \mu \mathrm{m}$ over $40 \mu \mathrm{m}$ & $\begin{array}{l}0.062 \% / \mu \mathrm{m} \text { over } 45 \mu \mathrm{m} \\
\text { then } \\
0.014 \% / \mu \mathrm{m} \text { over } 65 \mu \mathrm{m}\end{array}$ & $0.010 \% / \mu \mathrm{m}$ over $160 \mu \mathrm{m}$ \\
\hline & $/ /$ & $\begin{array}{l}0.049 \% / \mu \mathrm{m} \text { over } 45 \mu \mathrm{m} \\
\text { then } \\
0.020 \% / \mu \mathrm{m} \text { over } 40 \mu \mathrm{m}\end{array}$ & $\begin{array}{l}0.037 \% / \mu \mathrm{m} \text { over } 35 \mu \mathrm{m} \\
\text { then } \\
0.013 \% / \mu \mathrm{m} \text { over } 105 \mu \mathrm{m}\end{array}$ & $\begin{array}{l}0.011 \% / \mu \mathrm{m} \text { over } 135 \mu \mathrm{m} \\
\text { then } \\
0.004 \% / \mu \mathrm{m} \text { over } 195 \mu \mathrm{m}\end{array}$ \\
\hline & $\perp$ & $0.045 \% / \mu \mathrm{m}$ over $40 \mu \mathrm{m}$ & $\begin{array}{l}0.038 \% / \mu \mathrm{m} \text { over } 40 \mu \mathrm{m} \\
\text { then } \\
0.009 \% / \mu \mathrm{m} \text { over } 95 \mu \mathrm{m}\end{array}$ & $\begin{array}{l}0.009 \% / \mu \mathrm{m} \text { over } 155 \mu \mathrm{m} \\
\text { then } \\
0.004 \% / \mu \mathrm{m} \text { over } 165 \mu \mathrm{m}\end{array}$ \\
\hline
\end{tabular}




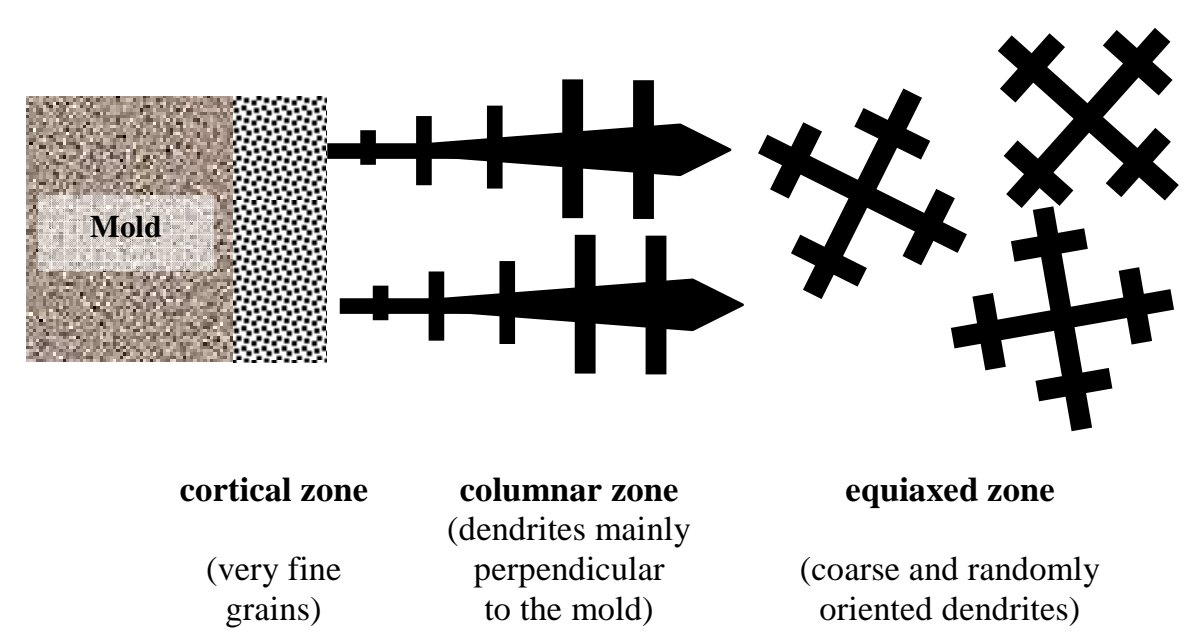

Figure 1 The three different microstructure zones which can be met from the mold wall in a metallic piece obtained by a classical foundry way

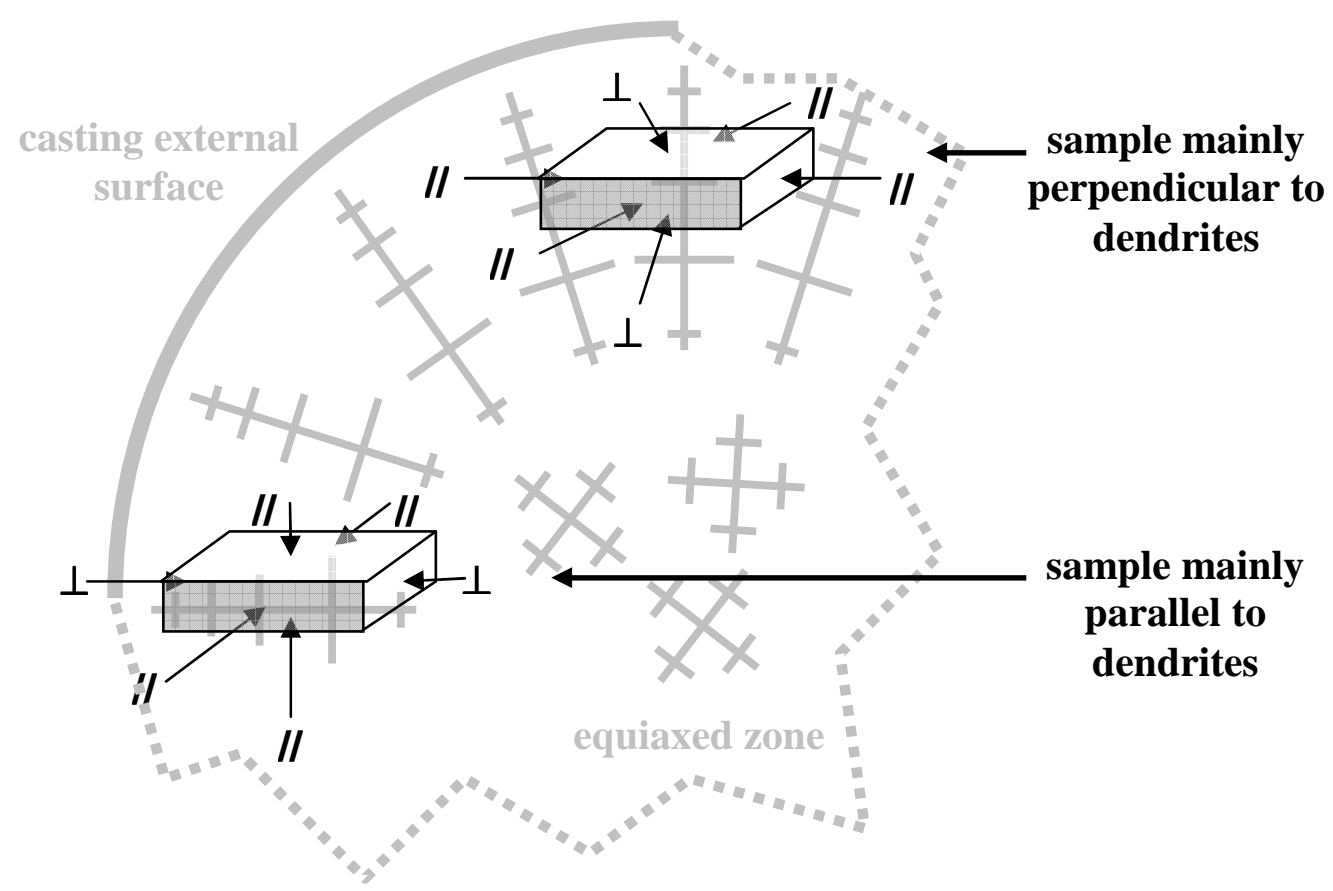

Figure 2 Cutting modes for samples mainly parallel or mainly perpendicular to dendrites 

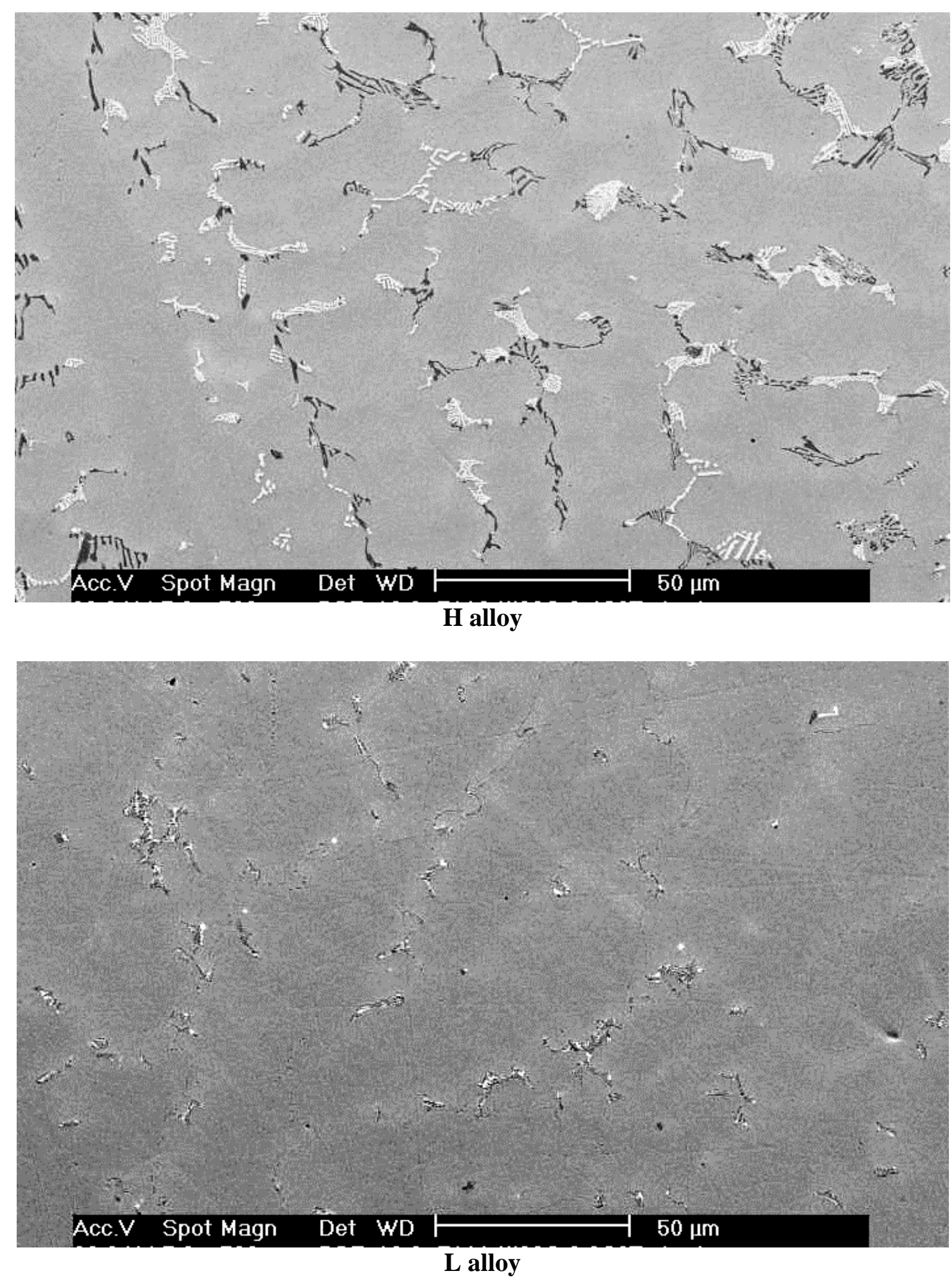

Figure 3 As cast microstructures of the two alloys 
L alloy $1200^{\circ} \mathrm{C}$

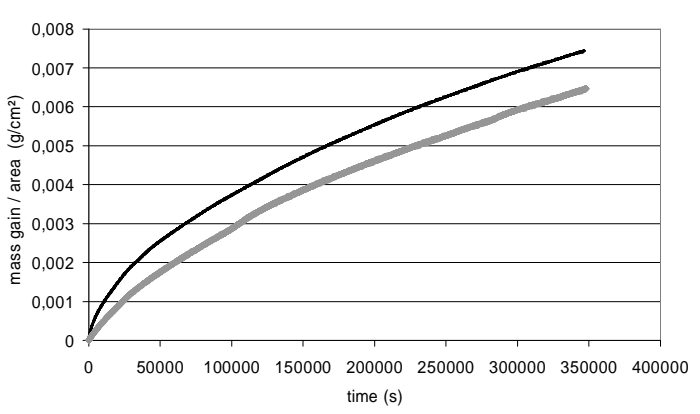

L alloy $1100^{\circ} \mathrm{C}$

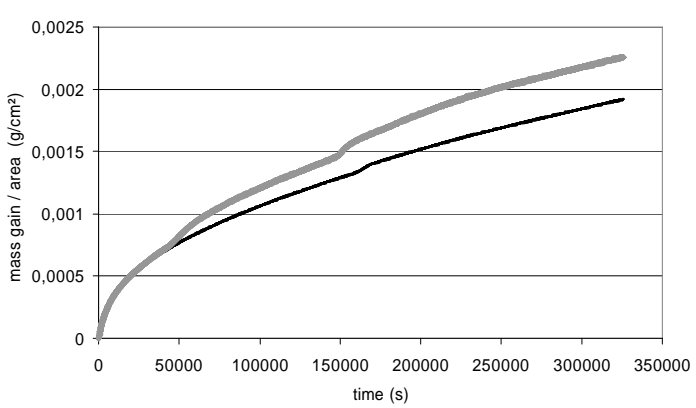

L alloy $1000^{\circ} \mathrm{C}$

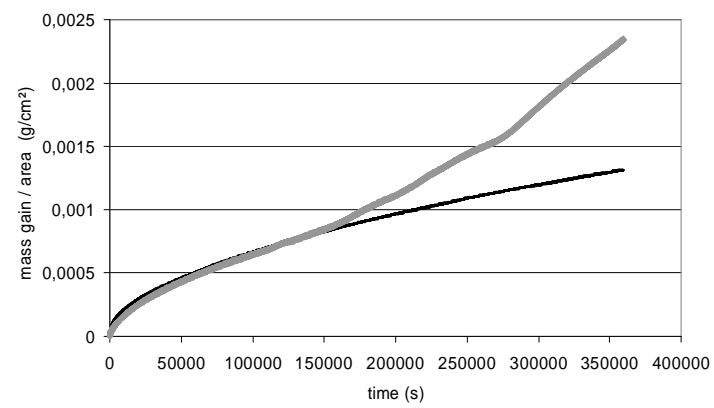

H alloy $1200^{\circ} \mathrm{C}$

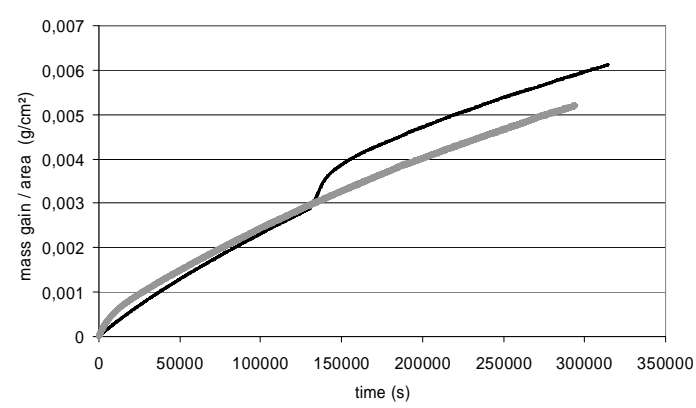

H alloy $1100^{\circ} \mathrm{C}$

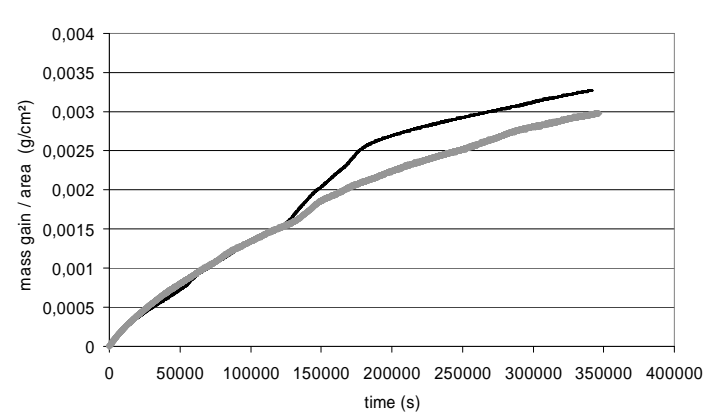

H alloy $1000^{\circ} \mathrm{C}$

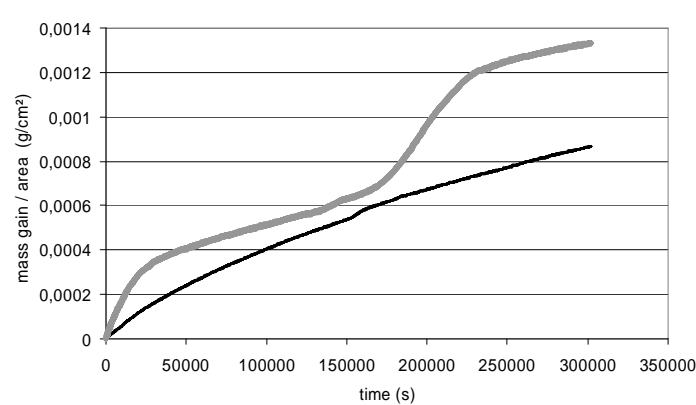

\begin{tabular}{l} 
- para \\
- perp \\
\hline
\end{tabular}

Figure 4 Mass gain curves for the two orientation plotted on a same graph for a given alloy and a given temperature (first linear parts were removed from all curves here) 


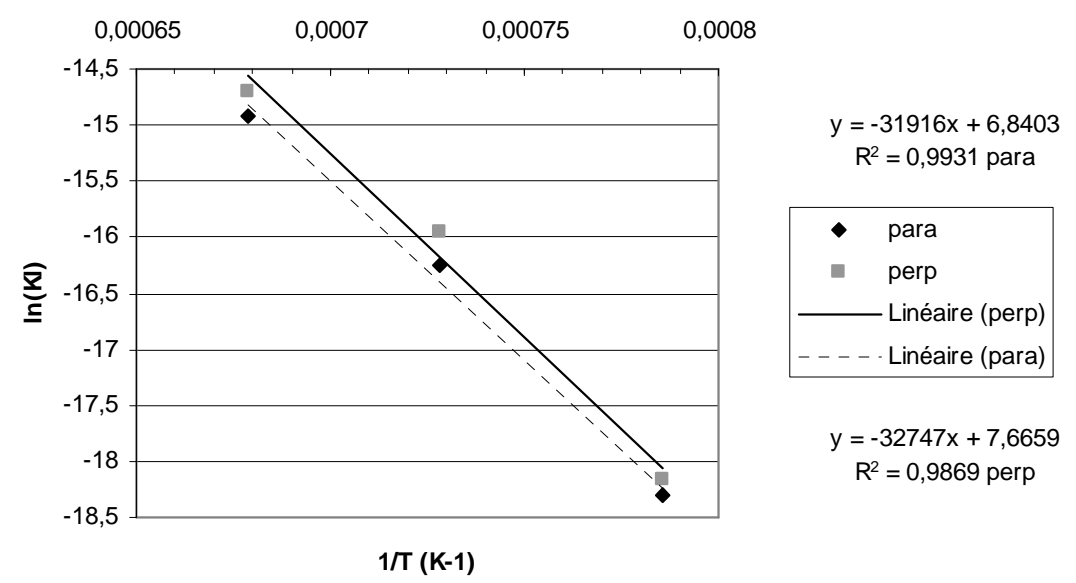

Figure 5 Variation with temperature of the global $\mathrm{K}_{1}$ values (expressed in $\mathrm{g} \cdot \mathrm{cm}^{-2} \cdot \mathrm{s}^{-1}$ ) plotted in an Arrhenius graph (here for $\mathrm{H}$ alloy and the two orientations)

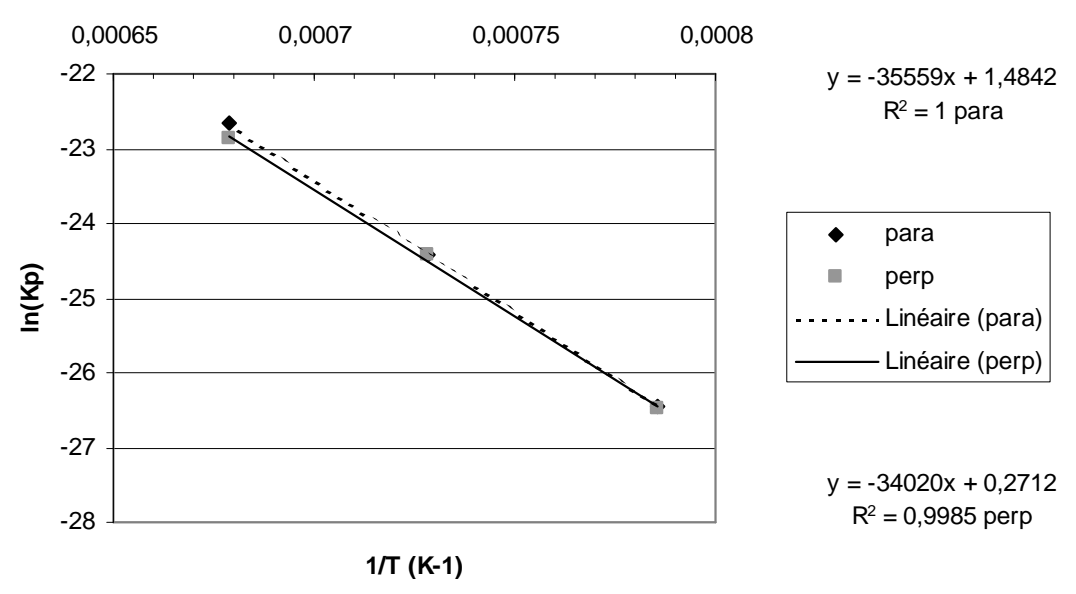

Figure 6 Variation with temperature of the uncoupled $\mathrm{Kp}$ // and $\mathrm{Kp} \perp$ values (expressed in $\mathrm{g}^{2} \cdot \mathrm{cm}^{-4} \cdot \mathrm{s}^{-1}$ ) plotted in an Arrhenius graph (here for $\mathrm{H}$ alloy and the two orientations) 


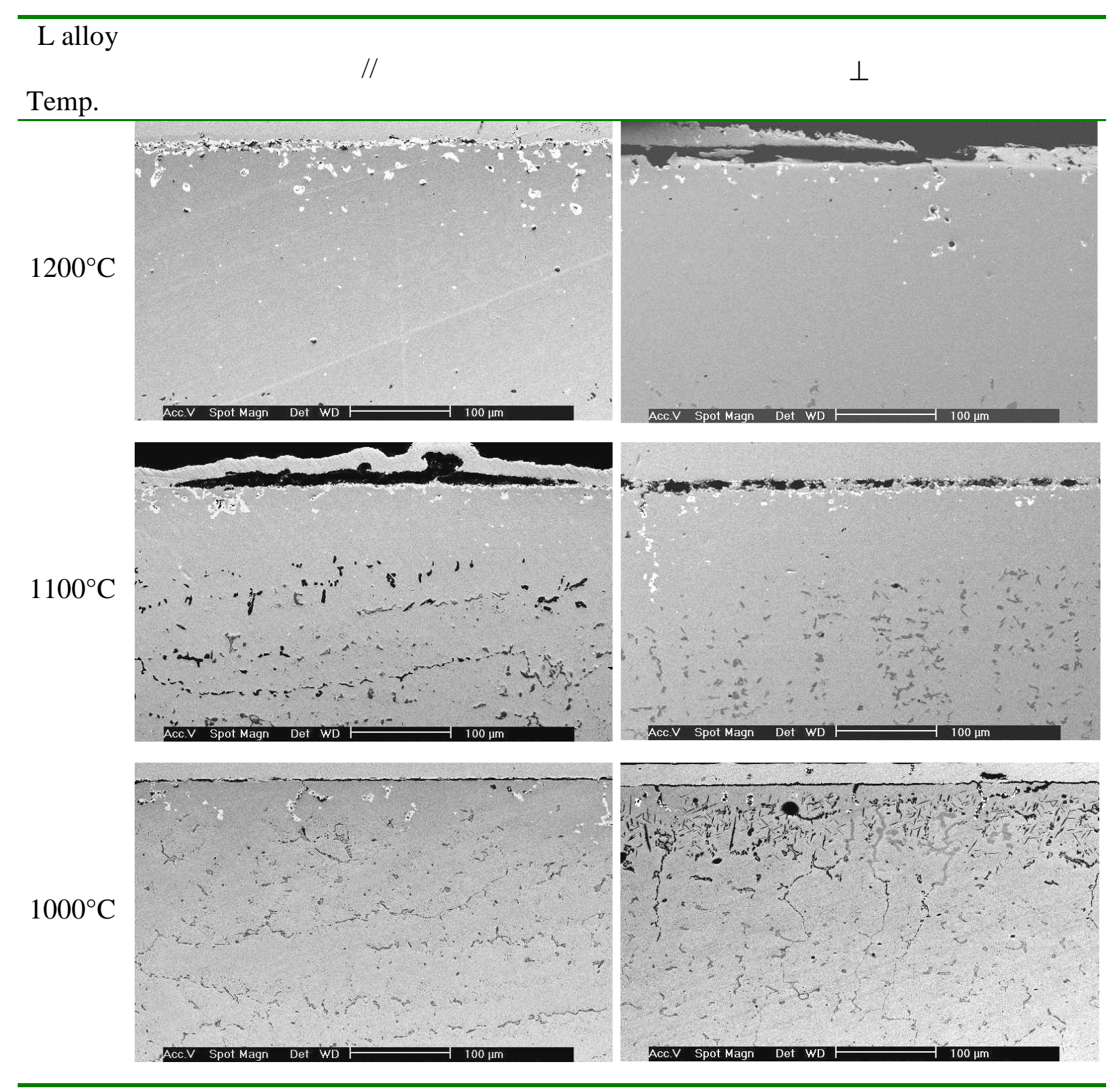

Figure 7 Surface microstructural state of all L-alloy samples after oxidation test 


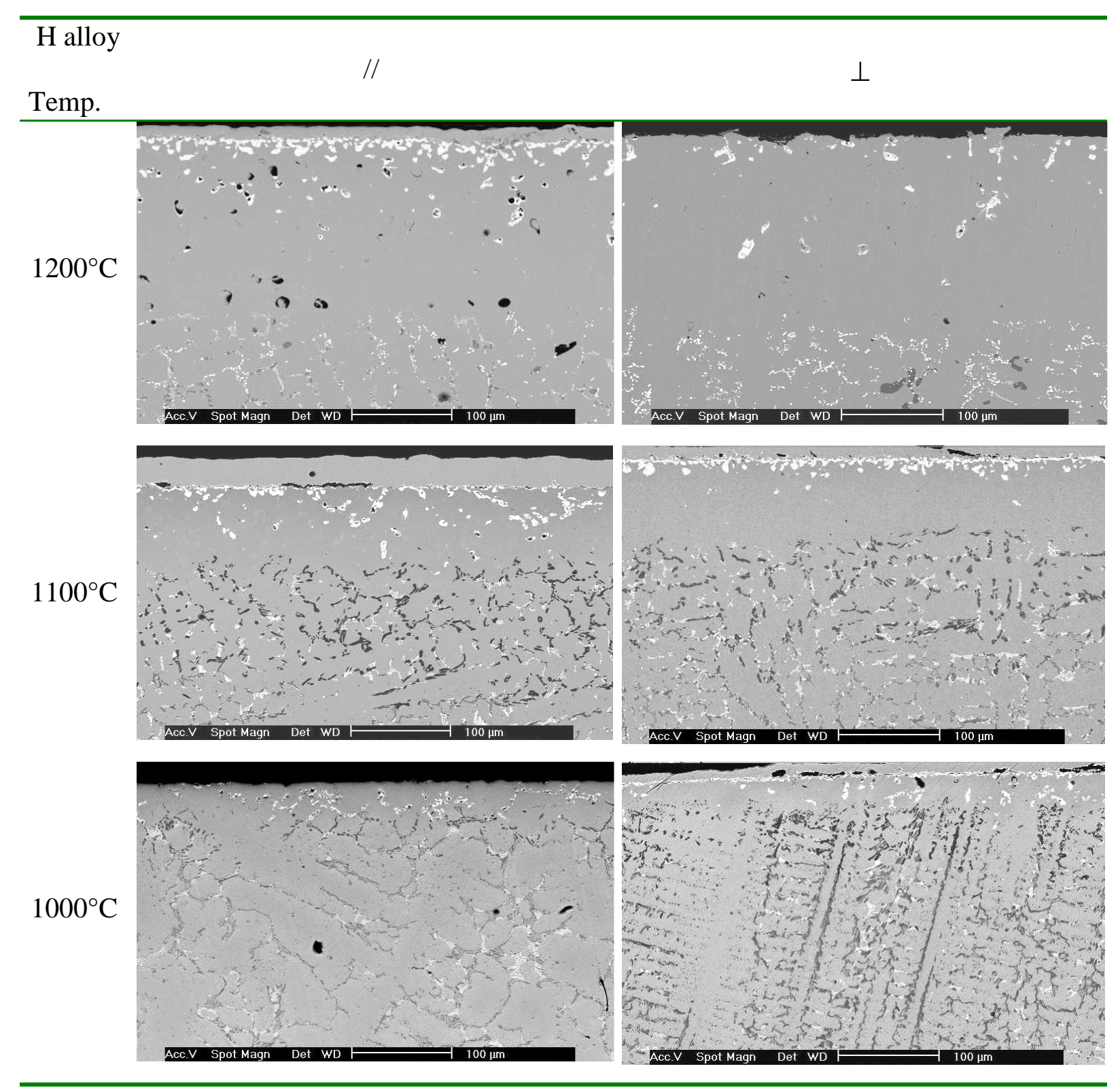

Figure 8 Surface microstructural state of all $\mathrm{H}$-alloy samples after oxidation test 


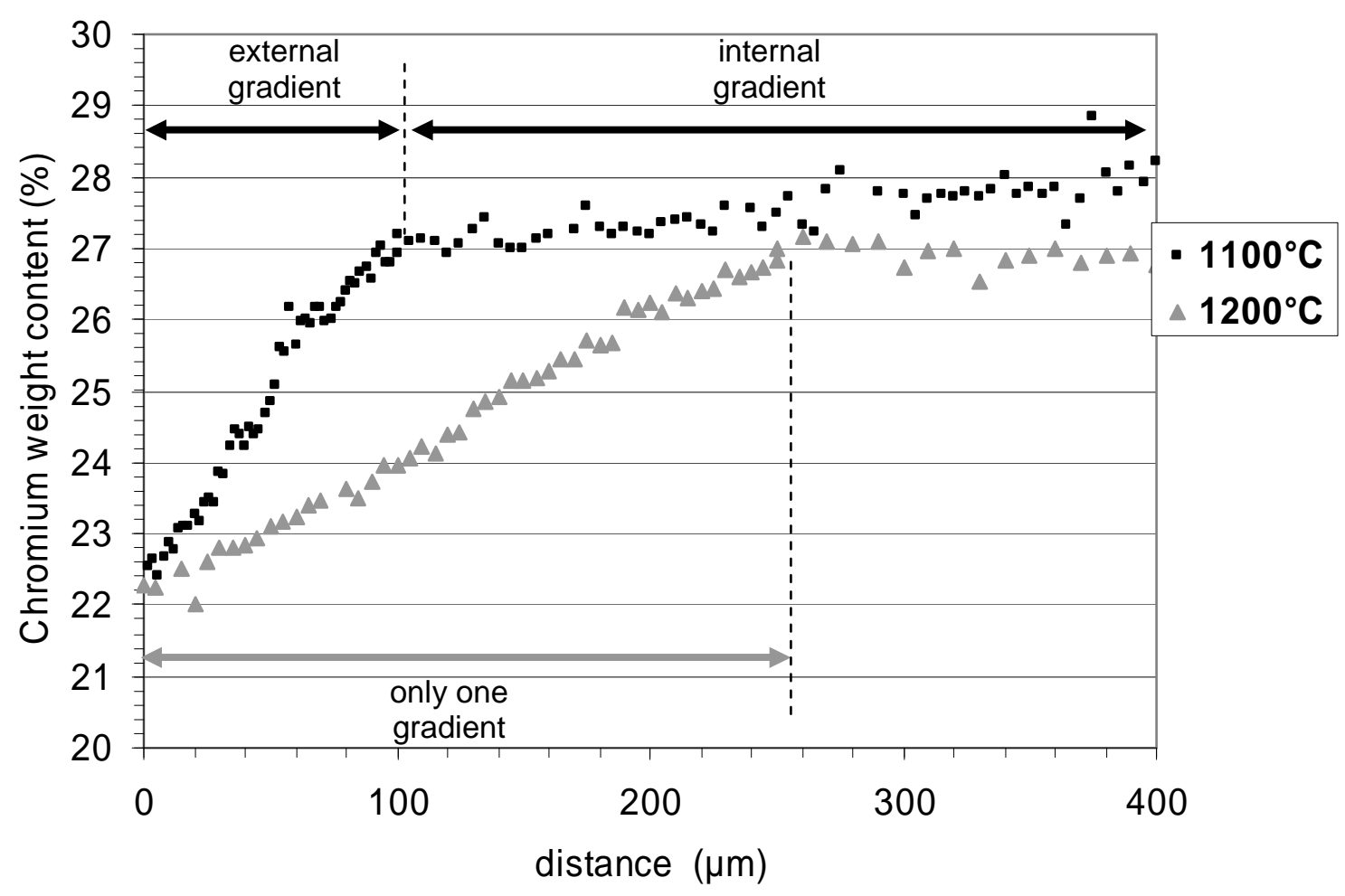

Figure 9 Example of the two types of $\mathrm{Cr}$ profiles with two gradients or only one but deeper (here L alloy after oxidation for 100 hours at $1100^{\circ} \mathrm{C}$ and at $1200^{\circ} \mathrm{C}$ ) 